\title{
Self-medication among Cancer Patients in Mahavir Cancer Sansthan, Patna
}

\author{
Soni ${ }^{*}$ and Kushwaha $\mathrm{AK}^{2}$ \\ ${ }^{1}$ Department of Pharmacology, All India Institute of Medical Sciences, Patna, Bihar, India \\ ${ }^{2}$ Department of Surgical Oncology, Mahavir Cancer Sansthan, Patna, Bihar, India
}

\begin{abstract}
Introduction: Cancer patients self-medicate themselves for the treatment for coexisting diseases with many over the counter drugs along with chemotherapy. A complete analysis was done on various aspect of self-medication among cancer patients.

Methods: A questionnaire-based study was done in the Out Patient Department of Mahavir Cancer Sansthan, a study was done in a single sitting. 32 patients voluntarily participated in the study among the 54 patients who attended the evening OPD.

Results: Eighty-seven per cent of the subjects reported to be taking self-medication, $25 \%$ reported to be taking ayurvedic drugs of which the majority reported to be taking for pain. The majority reported the reason for selfmedication to be quick relief and 56\% stated relief after medication.

Conclusion: This observational study gives relevant data to identify the potential determinant of self-medication among cancer patient and possible measures required to prevent this practice.
\end{abstract}

Keywords: Cancer; Self-medication

\section{INTRODUCTION}

It is estimated that around 2.25 million people in India are affected with cancer [1] and around 11,57,294 lakh patients are diagnosed every year according to Indian Council of Medical Research data [2]. These patients suffer from a wide range of symptoms related to cancer or related to cancer treatment. Rampant and irrational use of self-medication is very common in this patient. In addition to prescribed drugs, many cancer patients self- medicate with over-the-counter medications (OTCs) [3], vitamins, dietary supplements, herbs and other items [4]. There have been reports that these drugs may interfere with the chemotherapy drugs causing reduced efficacy or tumour resistance [5].

Self-medication is the selection and use of medicines by individuals to treat self-recognized illness or symptoms. It is one of the components of self-care which is defined by World Health Organization (1998) as what people do for their own selves to establish and maintain health, prevent, and deal with illness [6]. Self-medication not necessarily means the consumption of modern medicines but also includes herbs and home remedies [7]. Although in developed countries it is mainly restricted to over the counter medicine but in developing countries, it may occur with both over the counter medicine and prescription only medicine. In the majority of illness, self-medication is the first option which makes it a common practice worldwide. Selfmedication if practised rationally will reduce the load on medical services by reducing time and cost especially in economically deprived countries with limited health care resources like ours. However, if practised irrationally it is going to raise the concern of misdiagnosis as well as increase the load of adverse drug reaction, the emergence of drug resistance and drug dependence. Cases of self-medication reported all over the world shows that in developing countries like India selfmedication are the most preferred mode of self- care by the patient. Lack of strictness in drug marketing regulation and aggressive marketing campaigns by pharmaceutical companies have promoted self-medication to such extent that it has become a global health problem.

"Correspondence to: Soni, Senior Resident, Department of Pharmacology, All India Institute of Medical Sciences, Patna, Bihar, India, E-mail: dr.soni.rmch@gmail.com

Received: March 26, 2019; Accepted: April 16, 2019; Published: April 23, 2019

Citation: Soni, Kushwaha AK (2019) Self-medication among Cancer Patients in Mahavir Cancer Sansthan, Patna. J Clin Exp Pharmacol 9:260. doi: $10.4172 / 2161-1459.1000260$

Copyright: (C2019 Soni, et al. This is an open-access article distributed under the terms of the Creative Commons Attribution License, which permits unrestricted use, distribution, and reproduction in any medium, provided the original author and source are credited. 
Although self-medication by cancer patient has been reported but no such descriptive analytical study has been conducted in the northern part of India. To get more detailed information regarding alternative and other drugs taken by cancer patient we conducted a questionnaire-based study. The questions were framed in patient language i.e., Hindi for their convenience. All possible determinants of self-medication were included in the study. Patients were also allowed to give their own opinion if any.

\section{AIMS AND OBJECTIVES}

1. To explore the pattern of self-medication taken by a cancer patient.

2. Most probable determinants for such practices.

3. Most common drug used in self-medication.

4. Sources of information for self-medication.

5. The current attitude toward self-medication.

\section{RESEARCH METHODOLOGY}

A questionnaire-based study was conducted among cancer patients in Mahavir Cancer Sansthan, Patna in evening Out Patient Department. Voluntary participants were included in the study. A brief description of the nature of the study and procedure of completing the questionnaire was explained to patients taking part in the study. Questionnaire was divided in 3 sections $\mathrm{A}, \mathrm{B}$ and $\mathrm{C}$.

Section A started with three demographic questions name, age and sex followed by the status of their present health and the final question asking whether they are taking self-medication or not. Section B need to be attended by only those who had ticked for self-medication. Section B contained nine questions

1. Self-medication you are most commonly following

2. Source of information used for self-medication

3. Source of drugs used for self-medication

4. Indication for self-medication

5. Drugs commonly taken by you for self-medication

6. Reason for taking self-medication

7. Have you got relieved after taking medication?

8. Have you experienced any adverse effect after taking medication? if yes please mention

9. Awareness of various aspect of self-medication before taking medicine

Section $\mathrm{C}$ need to be attended by only those who have never taken self-medication it consisted of only one question of the reason for not taking self-medication with exhaustive options.

Section D was for both group $A \& B$ and consisted of two questions

1. Your current attitude toward self -medication
2. Your current attitude to prevent the growing trend of selfmedication

Study design: Observational \& analytical study

Study duration: 1 Seating's

Sample size: 32 cancer patients

\section{RESULTS}

54 subjects were asked to participate in the study out of which 22 refused and 32 participated in the study. Out of 32 half of the patients were of $30-50$ age groups. Majority of them were taking self-medication (87\%). Rest of the patient did not take self-medication due to lack of knowledge regarding the disease or medicine.

Allopathic medicine was the most common medicine used by these patients (68\%), with Ayurvedic (25\%) and Homeopathic (6\%) to follow. Chemists were the principle source of information regarding self-medication along with family and friends. Medical stores were the commonest source of these drugs (75\%) followed by local vendors (25\%).

Pain alone (33\%). Pain along with cough and cold (0.6\%), cough and cold alone (13\%). Cough and cold along with fever and headache $(0.6 \%)$. Fever alone $20 \%$. One patient took selfmedication for jaundice.

Quick relief+time saving-13\%

Time saving + small illness- $0.6 \%$

Quick relief+time saving+ unavailability of health services-13\%

Quick relief+unavailability of health services-20\%

Minor illness+unavailability of health services- $0.6 \%$

Quick relief ${ }^{+}$small illness ${ }^{+}$cost effictiveness-20\%

Rest had multiple reasons for taking self-medication including confidence of knowledge, to avoid the crowd, the doctor will prescribe the same drug. Antipyretics along with analgesic were commonly taken drugs followed by antacids and laxatives. Some also took ayurvedic preparations. Upon asking whether the use of these drugs they got relieved of their symptoms around $56 \%$ patient had positive response while $44 \%$ thought it did not relieve their symptoms. $92 \%$ of the patients were aware of the expiry date of the drug.

Around $37 \%$ of patient thought that self-medication is acceptable if taken during an emergency while the majority thought it to be justifiable when taken for minor illness (Figure 1 ). Around $12 \%$ of patients were of the opinion that they will continue self-medication mostly due to above-mentioned reasons (Table 1).

Regarding their current attitude to prevent the growing trend of self-medication majority were of the opinion to limit the medicine without a valid prescription and strict rules against pharmaceutical advertisement. Some thought that health professionals should be prompted to give proper instruction and explain what is prescribed. Awareness regarding the adverse 
effect of self-medication should be promoted. Around 31\% of patients had no opinion regarding this (Table 2).

Table 1: Demographic details of the patients.

\begin{tabular}{ll}
\hline Age group (years) & Number of patients $(\mathbf{n})$ \\
\hline $10-20$ & 2 \\
\hline $21-30$ & 4 \\
\hline $31-40$ & 6 \\
\hline $41-50$ & 10 \\
\hline $61-60$ & 6 \\
\hline Total & 4 \\
\hline
\end{tabular}

Table 2: Education details of the patients.

\begin{tabular}{ll}
\hline Education level & No. of patients $(\mathbf{n})$ \\
\hline Up to class 6 & 19 \\
\hline Class 7- Class 10 & 10 \\
\hline Class 11 and Above & 3 \\
\hline Total & 32 \\
\hline
\end{tabular}

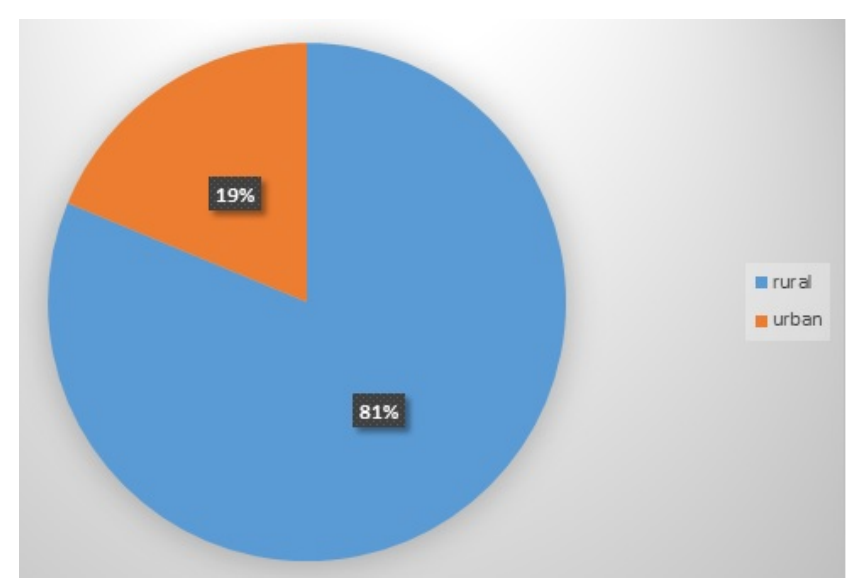

Figure 1: Residential status of the patients.

\section{DISCUSSION}

The study shows that self-medication is very common among cancer patients. Around $87 \%$ of the patient took self-medication for various reasons. Other researchers have found around half of their patient took self -medications. Apart from allopathic, cancer patients are also taking ayurvedic drugs as an alternative to treat their cancer or to treat their co-morbid condition. The majority are taking self-medication for quick relief.

Lack of health services is an important determinant for taking self-medication [8]. With a larger population residing in the village most patients do not have access to proper health care facilities promoting not only delay in diagnosis of disease but also rampant use of over the counter medicine. Pain and fever were the most common symptoms for self-medication [9]. This was followed by a cough and cold. Pain is a very common symptom in terminal stages of cancer. Poor economic status along lack of supply of pain medicines like morphine in cancer centre promotes the use of over the counter medicines. Some resort to ayurvedic or herbal preparations for the relief of their symptoms. These drugs may also increase the toxicity of chemotherapy drugs. Studies have reported a probable increase in nephrotoxicity upon taking many over the counter drugs along with chemotherapy $[10,11]$. Symptoms like constipation are very common among patients taking chemotherapy explaining the use of laxatives in these populations.

It was very surprising to know that although we include many options in our questionnaire list for the source of information of self-medication, the majority gave their own opinion of obtaining such information from quacks and chemists. Lack of strict rules and ignorance among the population is the main reason behind this practice. On asking them their current attitude toward self-medication majority had no opinion most probably because of the lack of knowledge [12,13].

\section{CONCLUSION AND RECOMMENDATIONS}

Based on our study we recommend the following measures to reduce self-medication among cancer patients.

- Improvement of health care facilities.

- The strict rule against medicine supply without a valid prescription.

- Promotion of awareness among people regarding the adverse effect of self-medication.

However, we recommend larger population-based studies to evaluate other determinants of reasons for taking selfmedication and also for experimental studies to evaluate the pharmacodynamic interaction of alternative medicine when taken concomitantly with cancer drugs.

\section{CONFLICT OF INTEREST}

None

\section{REFERENCES}

1. http://cancerindia.org.in/cancer-statistics

2. https://www.icmr.nic.in/

3. US National Library of Science. Medical Encyclopedia. Medline Plus. 2009.

4. Goldstein MS, Brown ER, Ballard-Barbash R, Morgenstern H, Bastani $\mathrm{R}$, et al. The use of complementary and alternative medicine among California adults with and without cancer. Evid Based Complement Alternat Med 2005;2:557-565.

5. Nicholas HG, Holoford MB. Pharmacokinetics and Pharmacodynamics: Rational Dosing and the Time Course of Drug Action. In: Katzung BG, editor. Basic and Clinical Pharmacology. Ninth ed. Lange Medical Books/McGraw-Hill; New York, USA. 2004;34-50. 
6. World Health Organisation. The role of the pharmacist in self-care and self-medication: Essential medicines and health products information portal. A World Health Organisation Resource. 1998.

7. Bennadi D. Self-medication: A current challenge. J Basic Clin Pharm 2014;5:19-23.

8. Shord SS, Thompson DM, Krempl GA, Hanigan MH. Effect of concurrent medications on cisplatin-induced nephrotoxicity in patients with head and neck cancer. Anticancer Drugs 2006;17:207-215

9. Health News. The Hindu Sci- Tech. 2019.

10. MedicineNet Health Solutions. Medical definition of adverse effects. 2018.
11. Whyte CA, Tepper SJ. Adverse effects of medications commonly used in the treatment of migraine. Expert Rev Neurother 2019;9:1379-1391.

12. Lescure D, Paget J, Schellevis F, van Dijk L. Determinants of SelfMedication with Antibiotics in European and Anglo-Saxon Countries: A Systematic Review of the Literature. Front Public Health 2018;6:370.

13. Nagarajaiah BH, Kishore MS, Kumar NSS, Panchakshari P. Prevalence and pattern of self-medication practices among population of three districts of South Karnataka. Natl J Physiol Pharm Pharmacol 2016;6:296-300 